\title{
LIČNOST I KARCINOM DEBELOG CRIJEVA
}

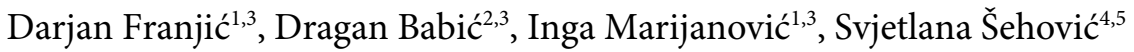 \\ ${ }^{1}$ Klinika za onkologiju Sveučilišne kliničke bolnice Mostar \\ ${ }^{2}$ Klinika za psihijatriju Sveučilišne kliničke bolnice Mostar \\ ${ }^{3}$ Fakultet zdravstvenih studija Sveučilišta u Mostaru \\ 88000 Mostar, Bosna i Hercegovina \\ ${ }^{4}$ Kantonalna bolnica „Dr. Safet Mujić“" Mostar \\ ${ }^{5}$ Madicinski fakultet Sveučilišta u Mostaru
}

Rad je primljen 12.06.2021. Rad je recenziran 26.06.2021. Rad je prihvaćen 09.07.2021.

\section{SAŽETAK}

Karcinom debelog crijeva jedna je od najučestalijih zloćudnih bolesti i jedan je od glavnih javno-zdravstvenih opterećenja u svijetu. Pojedina istraživanja ističu da su za nastanak karcinoma debelog crijeva uz navedene vanjske rizične čimbenike odgovorne i određene karakteristike ličnosti pojedinca te da emocionalnije osobe češće obolijevaju od karcinoma debelog crijeva. Mnoga istraživanja ukazuju na postojanje povezanosti između određenih dimenzija ličnosti s kvalitetom života i sposobnošću oporavka u oboljelih od karcinoma debelog crijeva. Uloga ličnosti kao prediktora za pojavnost karcinogene bolesti tema je kontroverze koja traje desetljećima. Rezultati pojedinih studija pokazuju da prisutnost negativnih karakteristika ličnosti utječe na lošiju kvalitetu života u osoba kojima je dijagnosticiran karcinom probavnog sustava. Pojedine studije ističu da karakteristike ličnosti imaju značajan utjecaj na razvoj i progresiju karcinoma debelog crijeva. Iako se ekstraverzija povezuje s boljom kvalitetom života u oboljelih od karcinoma debelog crijeva, u nekim je istraživanjima povezana s povećanim rizikom od razvoja malignih bolesti, vjerojatno kao rezultat veće sklonosti rizičnom ponašanju. Neuroticizam je definiran kao osobina ličnosti koja se najčešće povezuje sa simptomima ka što su umor, niža razina kvalitete života i depresija. Teorijska saznanja nalažu da karakteristike ličnosti imaju važnu ulogu u ishodu liječenja oboljelih od karcinoma debelog crijeva. Cilj ovog rada bio je istražiti dosadašnja saznanja o povezanosti karakteristika ličnosti s kvalitetom života $\mathrm{i}$ sposobnošću oporavka u osoba oboljelih od karcinoma debelog crijeva.

Ključne riječi: Ličnost, karcinom, debelo crijevo

Kontakt osoba;

Darjan Franjić, mag. rad. teh., doktorand

E-mail: darjan.franjic@fzs3.sum.ba 


\section{UVOD}

Karcinom debelog crijeva jedna je od najučestalijih zloćudnih bolesti i jedan je od glavnih javnozdravstvenih opterećenja u svijetu, osobito u razvijenim zemljama. Zbog toga je karcinom debelog crijeva izazov istraživačima najrazličitijih područja zdravstvenih i medicinskih znanosti. Nalazi se na trećem mjestu zloćudnih bolesti u oba spola, a po smrtnosti se nalazi na drugom mjestu u razvijenim zemljama. Pojavnost raste s dobi, počinje rasti iznad 40. godine života, da bi značajnije porasla između 50. i 55. godine, a kasnije raste s godinama geometrijskom progresijom. Razlike među spolovima u zadnjim se godinama izjednačavaju u pojavnosti i smrtnosti. Iako su za nastanak karcinoma debelog crijeva najčešće odgovorni vanjski rizični čimbenici (pušenje, pijenje alkohola, nezdrava prehrana, tjelesna neaktivnost), pojedina istraživanja ističu da su za nastanak karcinoma debelog crijeva uz navedene vanjske rizične čimbenike odgovorne i određene karakteristike ličnosti pojedinca te da emocionalnije osobe češće obolijevaju od karcinoma debelog crijeva (1-3). Razvoj psihologije ličnosti obilježavaju brojne kontroverzije, kako u odnosu na teoriju, tako i u pogledu istraživanja. Najveći problemi psihologije ličnosti su postojanje velikog broja teorija ličnosti, znatne razlike između tih teorija, načina na koji su nastale, nejasne relacije između njih te nepostojanje općeg prihvaćenog modela ličnosti (4). Postavljanje definicije za ljudsku ličnost vrlo je teško. Problem je kako postaviti definiciju koja će obuhvatiti sve aspekte ličnosti, uključujući unutrašnje karakteristike, socijalne efekte, kvalitete uma, tjelesne karakteristike, odnose s drugima i unutrašnje ciljeve. Stručnjaci i znanstvenici se slažu da se ličnost odnosi na one značajke osobe koje objašnjavaju relativno trajne i stabilne obrasce osjećanja, razmišljanja i ponašanja (5). Karakteristike ličnosti opisuju prosječne tendencije u ponašanju neke osobe, a osobine ličnosti podrazumijevaju dosljedne obrasce načina na koji se pojedinci ponašaju, misle i osjećaju $(6,7)$. Susan Cloninger na osnovu pregleda glavnih teorija ličnosti navodi da ličnost u početku obuhvaća biološki determinirane, odnosno naslijeđene komponente, koje su po svojoj prirodi slične onima kod drugih osoba, ali su i u određenoj mjeri različite. Prema njoj, ličnost sadrži aspekt njenog razvoja i uzajamnog djelovanja (interakcije) naslijeđa, okoline i aktivnosti pojedinca. U ovoj definiciji je istaknuto da smo u određenoj mjeri slični drugima, dok smo donekle jedinstveni (8). Schultz pod ličnošću podrazumijeva jedinstvene, relativno trajne vanjske $\mathrm{i}$ unutrašnje aspekte karaktera osobe, koji djeluju na njeno ponašanje u različitim situacijama. Allport u svojoj definiciji osobinama ličnosti pridaje kvalitete dinamičnosti i organiziranosti. McCrae i Costa navode da su crte ličnosti dimenzije individualnih razlika u tendencijama očitovanja konzistentnih obrazaca mišljenja, osjećanja i aktivnosti. Navode da su crte ličnosti stabilne tokom života. Prema Skinneru ličnost je $\mathrm{u}$ najboljem slučaju repertoar ponašanja potaknut organiziranim skupom okolnosti u određenoj situaciji, odnosno skup reakcija na specifične stimulanse. Pojedini stručnjaci ističu smatraju da je ličnost jedinstvena varijacija pojedinca u okviru generalnog evolucijskog dizajna ljudske prirode, te da je izražena u vidu razvojnog obrasca dispozicijskih crta, karakterističnih prilagodbi i integrativnih životnih priča, inkorporiranih u kulturu, koja ih oblikuje i mijenja na složen način (9).

Cilj ovog rada bio je istražiti dosadašnja saznanja o povezanosti karakteristika ličnosti s kvalitetom života i sposobnošću oporavka u osoba oboljelih od karcinoma debelog crijeva.

\section{DIMENZIJE LIČNOSTI}

U znanstvenim biološkim istraživanjima najčešće se koristi Eysenckov model ličnosti (9). Prema Eysenckovoj teoriji osnovna biološka razlika u ličnosti nalazi se $u$ različitim razinama pobuđenosti živčanih sustava ovisno o poziciji pojedinca na dimenzijama ličnosti. Eysenckov hijerarhijski model ličnosti ima najčvršće utemeljenje u biologiji. On je crte ličnosti smatrao nasljednim u velikoj mjeri, odnosno smatrao je da imaju psihofiziološko utemeljenje. Crte koje je on u svom modelu izdvojio su ekstraverzija naspram introverziji, neuroticizam naspram emocionalnoj stabilnosti i psihoticizam (10).

Petofaktorski ili Big-Five model pretpostavlja postojanje pet širokih ortogonalnih faktora, tradicionalno nazvanih IE - introverzija-ekstraverzija, U - ugodnost, S savjesnost, ES - emocionalna stabilnost te I - intelekt, s time da pojedini istraživači koriste i druga imena za pojedine faktore, npr. otvorenost ili otvorenost za iskustva, kultura i imaginacija za isti peti faktor - faktor intelekta (4).

Ekstraverzija je dimenzija ličnosti koja se odnosi na osobine kao što su društven, komunikativan, govorljiv, otvoren, optimista, energičan, dinamičan, dominantan, samopouzdan, zatvoren, tih, povučen, nesocijabilan, usamljen, miran i slično. Osobe koje postižu visoke rezultate na skalama ekstraverzije, u odnosu na osobe koje su pozicionirane bliže polu introverzije, pokazuju veću brzinu točnosti, nižu razinu aspiracija, veće variranje u reakcijama, visoku produktivnost na testu tematske apercepcije, sporije uslovljavanje, inertnije reakcije na stres i nižu perceptualnu rigidnost (11). 
Neuroticizam je dimenzija koja uključuje: razdražljivost, osjetljivost, anksioznost, nestabilnost, impulzivnost, zabrinutost, pesimizam, stabilnost, ležernost, bezbrižnost i opuštenost. Simpatički nervni sistem osoba sa izraženim neuroticizmom reagira pretjerano, te ove osobe čini osjetljivim i na najmanje stresore. Ukoliko je kod osobe izražen neuroticizam, ne znači nužno da je razvila neku od anksioznih poremećaja (12).

Psihoticizam je obilježen agresivnošću, egocentrizmom i antisocijalnim ponašanjem. Za razliku od ekstraverzije i neuroticizma, biološka podloga psihoticizma nije u potpunosti razjašnjena. Eysenck psihoticizam dovodi u vezu s dopaminergičnim i serotonergičnim funkcijama. Za razliku od ekstraverzije i neuroticizma, za psihoticizam Eysenck nije našao neurofiziološke korelate. Ako osoba postiže visoke rezultate na skalama psihoticizma, ne potpada nužno pod dijagnozu psihoze (13).

\section{LIČNOST I KARCINOM}

Uloga ličnosti kao prediktora za pojavnost karcinogene bolesti tema je kontroverze koja traje desetljećima. Rizični čimbenici za pojavnost karcinoma mogu proizlaziti iz bioloških i okolinskih uvjeta, kao što su genetski defekti ili izloženost otrovnim kemikalijama, te iz obrazaca ponašanja koji su zdravstveno rizični (14). Karakteristike ličnosti imaju ključnu ulogu u načinu prilagodbe pojedinca na teške situacije u svakodnevnom životu pojedinca kao što je dijagnoza karcinoma (15). Personalna postavka upućuje na mogućnost povezanosti crta ličnosti i pojavnosti karcinogene bolesti, te je usko povezana s genetskom postavkom. Mnoge crte ličnosti su oblikovane pod genetskim utjecajem (16). Karakteristike ličnosti na tri načina povećavaju vjerojatnost pojave bolesti, posebno kod ljudi koji imaju i genetsku predispoziciju za neku bolest, i to povećanjem fiziološke aktivacije, smanjivanjem socijalne potpore, te interferiranjem sa zdravim ponašanjem (17). Istraživanja provedena $s$ ciljem utvrđivanja povezanosti pojavnosti karcinoma s pojedinim karakteristikama ličnosti upućuju na postojanje pozitivne korelacije između pojavnosti karcinoma, niskih rezultata na skalama neuroticizma i visokih na skali ekstraverzije (18). Stručnjaci su razradili postavku kako niski neuroticizam može u stvari značiti izostanak emocionalnog doživljavanja, pa možda i potiskivanje emocija. Bilo bi onda za očekivati da osobe $s$ visokim stupnjem emocionalnosti nisu toliko izložene pojavnosti karcinogene bolesti (19). Sukladno tome, drugi autori navode da među duševnim bolesnicima i osobito oboljelima od shizofrenije postoji manji broj oboljelih od karcinoma nego u općoj populaciji, pa je broj duševnih bolesnika s karcinomom manji za trećinu, nego što je to slučaj kod ostalog stanovništva (14). Karakteristike ličnosti su povezane s psihološkim i fizičkim simptomima vezanih za karcinom (20). Neke studije su pronašle značajnu povezanost između pojavnosti karcinoma i pojedinih karakteristika ličnosti pojedinca $(21,22)$. Wang i suradnici navode da je stupanj umora uzrokovan karcinomom povezan s psihoticizmom, ekstraverzijom/intraverzijom, neuroticizmom i lažnim subskalama Eysenckovog upitnika ličnosti (23). Yamaoka i suradnici navode da su pronašli pozitivnu korelaciju između kvalitete života, psihoticizma i ekstraverzije $\mathrm{u}$ osoba $\mathrm{s}$ različitim medicinskim stanjima (24). Istraživanja provedena $\mathrm{u}$ posljednjih nekoliko godina nisu nisu pronašla povezanost neuroticizma i ekstraverzije s pojavnošću karcinoma ili smrtnosti od karcinoma $(25,26)$. Nasuprot tome, pojedina istraživanja ukazuju na važnost uloge karakteristika ličnosti u odnosu na pojavnost karcinoma općenito, a naročito karcinoma debelog crijeva, te da emocionalnije osobe češće obolijevaju od karcinoma debelog crijeva (27).

\section{UTJECAJ DIMENZIJA LIČNOSTI NA KVALITETU ŽIVOTA OBOLJELIH OD KARCINOM DEBELOG CRIJEVA}

U dosadašnjim studijama najjače i najkonzistentnije veze između ličnosti i komponenti dobrobiti pronađene su za dimenzije ekstraverzije i neuroticizma, odnosno ugodnosti i savjesnosti. Pokazalo se da ekstraverzija i neuroticizam imaju jaku povezanost $s$ afektivnim komponentama subjektivne dobrobiti. Neuroticizam se povezuje s čestim iskustvom anksioznosti, nervoze, tuge i drugih neugodnih emocija, dok je ekstraverzija povezana s pozitivnim afektom (28). Ekstraverzija i neuroticizam utječu na subjektivnu kvalitetu života preko vjerojatnosti doživljavanja pozitivnih i negativnih emocija. Prema takvom bi shvaćanju, ekstraverti, u situacijama u kojima je to moguće, vjerojatnije doživljavali pozitivne emocije od introverata. Isto bi tako emocionalni nestabilni pojedinci u određenim situacijama vjerojatnije doživljavali negativne emocije od emocionalno stabilnih osoba. Na taj bi način objektivno slične okolnosti kojima su pojedinci različitih karakteristika ličnosti izloženi kod njih dovodile do različitih ishoda u pogledu subjektivne dobrobiti. Budući da je riječ o korelacijskim istraživanjima, moguće je da kauzalni mehanizam bude drugačiji. Moguće je da su karakteristike ličnosti povezane $s$ vjerojatnošću doživljavanja određenih situacija koje izazivaju veći ili 
manji osjećaj subjektivne dobrobiti. Moguće je da ekstraverti stvarno imaju više pozitivnih, a neurotičari više negativnih iskustava, te da to dovodi do razlika $\mathrm{u}$ subjektivnoj dobrobiti (29). Prisutnost psihičkih simptoma, osjećaja ljutnje i negativnih karakteristika ličnosti utječu na lošiju kvalitetu života u osoba kojima je dijagnosticiran karcinom probavnog sustava (28). Ispitanici koji boluju od karcinoma, a pritom imaju veći broj bodova na skali ekstraverzije, imaju manji rizik i strah od smrti. Karakteristike ličnosti imaju značajan utjecaj na razvoj i progresiju karcinoma debelog crijeva (30). Osobe koje boluju od karcinoma su uglavnom otvorene i imaju visoku razini na skali ekstraverzije $(31,32)$. Sharma i suradnici navode da postoji značajna povezanost između kvalitete života i ekstraverzije te da ekstraverzija negativno korelira s trajanjem postoperativnog oporavka u osoba liječenih od karcinoma debelog crijeva (32). Aschwanden i suradnici navode da su visoki rezultati na skali ekstraverzije povezani s višom razinom kvalitete života u osoba oboljelih od karcinomom debelog crijeva (30). Pojedini autori ističu da osobe koje su ekstravertne i imaju socijalnu podršku okoline doživljavaju posttraumatski rast (33).

Iako se $\mathrm{u}$ pojedinim studijama ekstraverzija povezuje s boljom kvalitetom života u osoba oboljelih od karcinoma debelog crijeva, ova dimenzija ličnosti je u nekim istraživanjima povezana s povećanim rizikom od razvoja malignih bolesti, vjerojatno kao rezultat veće sklonosti rizičnom ponašanju (34). Den Oudsten i suradnici navode da je neuroticizam definiran kao osobina ličnosti koja se najčešće povezuje s različitim aspektima preživljavanja karcinoma, kao što su umor, niža razina kvalitete života i depresija (35). Teorijska saznanja nalažu da karakteristike ličnosti imaju važnu ulogu u vezi za zdravlje pozitivnog ponašanja i ishoda liječenja u oboljelih od karcinoma debelog crijeva (36, 37).

\section{UTJECAJ LIČNOSTI NA SPOSOBNOST OPORAVKA OBOLJELIH OD KARCINOMA DEBEOG CRIJEVA}

Do danas su provedena brojna istraživanja koja ukazuju na povezanost i utjecaj pojedinih dimenzija ličnosti na sposobnost oporavka ili psihološku rezilijenciju u oboljelih od karcinoma debelog crijeva. Lu i suradnici navode da je rezilijencija značajan medijator u povezanosti između ekstraverzije i sreće pojedinca te da je rezilijencija značajan prediktor ekstraverzije i neuroticizma (38). Načini suočavanja sa stresnim situacijama i karakteristike ličnosti predstavljaju unutarnje zaštitne čimbenike koji utječu na rezilijenciju kod pojedinca $(39,40)$. Ewen i suradnici navode da su ekstraverti asertivni, energični, razgovorljivi i puni samopouzdanja prilikom suočavanja s nepoznatim situacijama (41). Navedene osobine su ključne za razvijanje rezilijencije. Pojedine studije su pronašle negativnu povezanost između neuroticizma i rezilijencije (42). Većina studija koje su provedene na temu povezanosti karakteristika ličnosti i rezilijencije ukazuju na postojanje pozitivne korelacije između ekstraverzije i rezilijencije (43-45). McDonnell i Semkovska navode da je viša razina na skali ekstraverzije povezana s višom razinom rezilijencije, te da su osobe $s$ ovakvim rezultatima imale manje izražene simptome depresije. Ispitanici koji su imali visoke rezultate na skali neuroticizma su imale nisku razinu rezilijencije. Posljedično, ispitanici s takvim rezultatima su imali jače izražene psihičke simptome. Ovakvi rezultati ukazuju na vjerojatnost da će intervencije za jačanje rezilijencije vjerojatno biti uspješnije u osoba koje imaju više rezultate na skali ekstraverzije (46). Hsieh i suradnici potvrđuju nalaze navedenih studija koji ukazuju da rezilijencija značajno pozitivno korelira s ekstraverzijom (47). Razlog za ovakve nalaze može biti u tome što ekstraverzija kao dimenzija ličnosti u sebi sadrži entuzijazam koji predstavlja pozitivnu emocionalnu osobinu. U skladu s time, viša razina ekstraverzije kod pojedinca značajno doprinosi jačanju i razvijanju rezilijencije (48). Robertson i suradnici navode da nisu pronađeni snažni dokazi koji ukazuju da je ekstraverzija prediktor razine rezilijencije kod pojedinca (49).

Kocjan i suradnici navode da postoji značajna negativna povezanost između neuroticizma i rezilijencije, te da nije pronađena značajna povezanost između ektraverzije i rezilijencije (50). Uzrok ovakvih nalaza može biti u tome što ekstraverzija pokriva avanturizam koji se odnosi na traženje uzbuđenja. Postoje saznanja da ova faceta ektraverzije u manjoj mjeri doprinosi višoj razini rezilijencije (49). Hulya i suradnici navode da je pronađena značajna povezanost na različitim razinama između karakteristika ličnosti i razine rezilijencije $\mathrm{u}$ odraslih osoba. U njihovoj studiji pronađena je značajna razlika u karakteristikama ličnosti između rezilijentnih i nerezilijentnih osoba. Najveća razlika je zabilježena $u$ dimenzijama ekstraverzija i neuroticizam. Ekstraverzija je pozitivno povezana $s$ razinom rezilijencije, dok je dimenzija ličnosti neuroticizam negativno povezana s rezilijencijom (51). Amstadter i suradnici su analizirali povezanost osobina ličnosti i psihološke rezilijencije. Rezultati njihovog istraživanja su pokazali da je najveća fenotipska i genetska povezanost dokazana između neuroticizma i rezilijencije. Dokazana je određena fenotipska i genetska povezanost i ostalih karakteristika ličnosti koje su uključene $u$ njihovo istraživanje (optimizam, samopoštovanje, altruizam) s razinom 
psihološke rezilijencije (52).

$\mathrm{U}$ odnosu na temu povezanosti rezilijencije kao osobine ličnosti s bolešću (53), karcinomom debelog crijeva (54) i karcinomom dojke (55) provedeno je nekoliko studija i na našem Sveučilištu koje pokazuju da rezilijencija i pozitivne dimenzije ličnosti utječu na brži oporavak. Pojedine studije navode da su psihički simptomi naročito izraženi u onkoloških bolesnika te da je vrlo bitno taj problem analizirati i kontrolirati uvođenjem raznih psiholoških intervencija (56).

\section{ZAKLJUČAK}

Karakteristike ličnosti imaju važnu ulogu u doživljaju i načinu suočavanja oboljelih s karcinomom debelog crijeva. Dosadašnja saznanja ukazuju da je ekstraverzija pozitivno povezana s kvalitetom života i sposobnošću oporavka oboljelih od karcinoma debelog crijeva. Neuroticizam i psihoticizam negativno utječu na razinu kvalitete života i sposobnosti oporavka oboljelih od karcinoma debelog crijeva.

\section{LITERATURA}

1. Guinney J, Dienstmann R, Wang X, de Reyniès A, Schlicker A, Soneson C, et al. The consensus molecular subtypes of colorectal cancer. Nat Med. 2015;21(11):1350-6.

2. Müller MF, Ibrahim AE, Arends MJ. Molecular pathological classification of colorectal cancer. Virchows Arch. 2016;469(2):125-34.

3. Wright M, Beaty JS, Ternent CA. Molecular markers for colorectal cancer. Surg Clin North Am. 2017;97(3):683-701.

4. Mlačić B, Knezović Z. Struktura i relacije Big Five markera i Eysenckova upitnika ličnosti: empirijska usporedba dvaju strukturalnih modela ličnosti. Društvena istraživanja: časopis za opća društvena pitanja. Zagreb. 1996;1(27):1-21.

5. Chamoro-Premuzic T, Furnham A. Personality, intelligence and approaches to learning as predictors of academic performance. Pers Individ Differ. 2008;44(7):1596-1603.

6. Pervin LA, Cervone D, John OP, editors. Psihologija ličnosti: teorije $\mathrm{i}$ istraživanja. Zagreb: Školska knjiga; 2008.

7. Tatalović V, Puhalo J. Povezanost osobina ličnosti, nade, optimizma i zadovoljstva životom odgojitelja predškolske djece. Napredak. 2016;157(12):205-220.
8. Cloninger S. Conceptual issues in personality theory. In: Corr UPJ, Matthews G, editors. The Cambridge handbook of personality psychology. New York: Cambridge University Press; 2009. p. 3-29.

9. Repišti S. Psihologija ličnosti: teorija i imperija. 1st ed. Sarajevo: IndeksLine; 2015.

10. Repišti S. Psihologija ličnosti: teorija i imperija. 2nd ed. Sarajevo: IndeksLine; 2016.

11. Weninger RL, Holder MD. Extraversion and subjective well-being. Int J Psychol Res. 2013;8(3):141172 .

12. Aldinger M, Stopsack M, Ulrich I, Appel K, Reinelt E, Wolff S, et al. Neuroticism developmental courses--implications for depression, anxiety and everyday emotional experience; a prospective study from adolescence to young adulthood. BMC Psychiatry. 2014 Aug 6;14:210.

13. Heaven PC, Ciarrochi J, Leeson P, Barkus E. Agreeableness, conscientiousness, and psychoticism: distinctive influences of three personality dimensions in adolescence. Br J Psychol. 2013 Nov;104(4):481-94.

14. Stokols D. Establishing and maintaining healthy environments: toward a social ecology of health promotion. Am Psychol. 1992;47:6-22.

15. Larsen RJ, Buss DM. Psihologija ličnosti: Područja znanja o ljudskoj prirodi. Zagreb: Naklada Slap; 2008.

16. Havelka M. Zdravstvena psihologija. Zagreb: Medicinski fakultet Sveučilišta u Zagrebu; 1995.

17. Nietzel MT, Bernstein DA, Milich R. Uvod u kliničku psihologiju. Zagreb: Naklada Slap; 2002.

18. Berndt H, Gunther H, Rothe G. Stress and Cancer. Toronto: C.J. Hogrefe; 1980.

19. Heaven PC, Ciarrochi J, Leeson P, Barkus E. Agreeableness, conscientiousness, and psychoticism: distinctive influences of three personality dimensions in adolescence. Br J Psychol. 2013 Nov;104(4):481-94.

20. Zimmermann C, Burman D, Swami N, Krzyzanowska MK, Leighl N, Moore M. Determinants of quality of life in patients with advanced cancer. Support Care Cancer. 2011 May;19(5):621-9.

21. Burack J, Blidner A, Flores H, Fitch T. Constructions and deconstructions of risk, resilience and wellbeing: a model for understanding the development of Aboriginal adolescents. Australas Psychiatry. 2007;15 Suppl 1:18-23.

22. Waller M. Resilience in ecosystemic context: 
evolution of the concept. Am J Orthopsychiatry. 2001;71(3):290-297.

23. Wang SH, He GP, Jiang PL, Tang LL, Feng XM, Zeng C, et al. Relationship between cancer - related fatigue and personality in patients with breast cancer after chemotherapy. Psychooncology. 2013; 22:23862390 .

24. Yamaoka K, Shigehisa T, Ogoshi K, Haruyama K, Watanabe M, Hayashi F, et al. Health-related quality of life varies with personality types: a comparison among cancer patients, non-cancer patients and healthy individuals in a Japanese population. Qual Life Res. 1998;7:535-544.

25. Schapiro IR, Ross-Petersen L, Saelan H, Garde $\mathrm{K}$, Olsen JH, Johansen C. Extroversion and neuroticism and the associated risk of cancer: a Danish cohort study. Am J Epidemiol. 2001;153:757-63.

26. Nakaya N, Bidstrup PE, Saito-Nakaya K, Frederiksen K, Koskenvuo M, Pukkala E, et al. Personality traits and cancer risk and survival based on Finnish and Swedish registry data. Am J Epidemiol. 2010;172(4):377-85.

27. Shun SC, Hsiao FH, Lai YH, Liang JT, Yeh KH, Huang J. Personality trait and quality of life in colorectal cancer survivors. Oncol Nurs Forum. 2011;38(3):221-8.

28. Bratko D, Sabol J. Osobine ličnosti i osnovne psihološke potrebe kao prediktori zadovoljstva životom: rezultati on-line istraživanja. Druš Istraž Zagreb. 2006;4-5(84-85):693-711.

29. Minami Y, Hosokawa T, Nakaya N, Sugawara Y, Nishino Y, Kakugawa Y, et al. Personality and breast cancer risk and survival: the Miyagi cohort study. Breast Cancer Res Treat. 2015;150:675-684.

30. Aschwanden D, Gerend MA, Luchetti M, Stephan Y, Sutin AR, Terracciano A. Personality traits and preventive cancer screenings in the Health Retirement Study. Prev Med. 2019;126:105763.

31. Sumalla EC, Ochoa C, Blanco I. Posttraumatic growth in cancer: reality or illusion? Clin Psychol Rev. 2009;29(1):24-33.

32. Sharma A, Sharp DM, Walker LG, Monson JRT. Patient personality predicts postoperative stay after colorectal cancer resection. Colorectal Dis. 2007;10:151-156.

33. Turhal NS, Demirhan S, Satici C, Cinar C, Kinar A. Personality traits in cancer patients. Asian Pac J Cancer Prev. 2013;14(8):4515-8.
34. Nakaya N, Tsubono Y, Hosokawa T, Nishino Y, Ohkubo T, Hozawa A. Personality and the risk of cancer. J Natl Cancer Inst. 2003;95(11):799-805.

35. Den Oudsten BL, Van Heck GL, Van derSteeg AF, Roukema JA, De Vries J. Predictors of depressive symptoms 12 months after surgical treatment of earlystage breast cancer. Psychooncology. 2009; 18:1230-1237.

36. Hypantis T, Paika V, Almyroudi A, Kampletsas EO, Pavlidis N. Personality variables as predictors of early non-metastatic colorectal cancer patients' psychological distress and health-related quality of life: A one-year prospective study. J Psychosom Res. 2011;70:411-421.

37. Sales PM, Carvalho AF, McIntyre RS, Pavlidis N, Hyphantis TN. Psychosocial predictors of health outcomes in colorectal cancer: a comprehensive review. Cancer Treat Rev. 2014;40(6):800-9.

38. Lu W, Wang Z, Liu Y, Zhang H. Resilience as a mediator between extraversion, neuroticism and happiness, PA and NA. Pers Individ Differ. 2014;63:128133.

39. Folkman S, Moskowitz JT. Coping: pitfalls and promise. Annu Rev Psychol. 2004;55(1):745-74.

40. Skodol AE. The resilient personality. In: Reich JV, Zautra AJ, Hall JS, editors. Handbook of Adult Resilience. New York: Guilford Press; 2010. p. 112-125.

41. Ewen RB. Personality: a topical approach: theories, research, major controversies, and emerging findings. New Jersey: Lawrence Erlbaum Associates Publishers; 1998.

42. Abdula MA, Amaal AM. Five factor personality traits and psychological resilience among secondary school students in Egypt. PERR. 2015;4(2):3-9.

44. Davey M, Eaker DG, Walters LH. Resilience processes in adolescents: personality profiles, self-worth, and coping. J Res Adolesc. 2003;18(4):347-362.

45. Furnham A, Crump J, Whelan J. Validating the NEO personality inventory using assessor's ratings. Pers Individ Differ. 1997;22(5):669-675.

46. McDonnell S, Semkovska M. Resilience as mediator between extraversion, neuroticism, and depressive symptoms in university students. J Posit Psychol. 2020;4(1):26-40.

47. Hsieh HF, Chen YM, Wang HH, Chang SC, Ma SC. Association among components of resilience and workplace violence-related depression among emergency department nurses in Taiwan: A cross-sectional study. J 
Clin Nurs. 2016;25(17-18):2639-2647.

48. Appleton L, Goodlad S, Irvine F, Poole H, Wall C. Patient's experiences of living beyond colorectal cancer: a qualitative study. Eur J Oncol Nurs. 2013;17(5):610-7.

49. Robertson I, Leach D, Dawson J. Personality and resilience: domains, facets, and non-linear relationships. IJSPW. 2018;2(3):2397-7698.

50. Kocjan GZ, Kavčić T, Avsec A. Resilience matters: Explaining the association between personality and psychological functioning during the COVID-19 pandemic. Int J Clin Health Psychol. 2021 Jan-Apr;21(1):100198.

51. Hulya E. The relationship between resilience and the big five personality traits in emerging adulthood. EJER. 2017;70:83-103.

52. Amstadter AB, Moscati A, Oxon MA, Maes HH, Myers JM, Kendler KS. Personality, cognitive/psychological traits and psychiatric resilience: a multivariate twin study. Pers Individ
Differ. 2016 Mar;91:74-79.

53. Franjić D, Marijanović I, Babić D. Karcinom debelog crijeva i rezilijencija. Zdravstveni glasnik. 2019;5:66-74.

54. Babić R, Babić M, Rastović P, Ćurlin M, Šimić J, Mandić K, et al. Resilience in health and illness. Psychiatr Danub. 2020 Sep;32(Suppl 2):226-232.

55. Boškailo E, Franjić D, Jurić I, Kiseljaković E, Marijanović I, Babić D. Resilience and quality of life of patients with breast cancer. Psychiatr Danub. 2021;33(4):572-579

56. Kvesić A, Babić D, Franjić D, Marijanović I, Babić R, Martinac M. Correlation of Religiousness with the Quality of Life and Psychological Symptoms in Oncology Patients. Psychiatr Danub. 2020 Sep;32(Suppl 2):254261. 